\title{
FINITE ELEMENT BEHAVIOR OF AA7075 UNDER SQUARE SHAPE OF STRIKER OF SPLIT HOPKINSON PRESSURE BAR WITH VARYING LOADS
}

DOI : 10.36909/jer.ICIPPSD.15511

\author{
Manish Kumar Gupta* \\ Department of Mechanical Engineering, National Institute of Technology Patna, Patna, 80005, \\ India. \\ *Email: gupta.manish102@gmail.com; Corresponding Author.
}

\begin{abstract}
To know the high strain rate behavior of aluminum alloy 7075 (AA7075) is very significant due to its vital uses in aviation, buildings, and automobile industries. Taylor impact test, projectile tests and split Hopkinson pressure bar are usually utilized to know the behavior of materials under high strain rate conditions. But due to lack of availabilities and very costly setups, various types of changes can't be done easily. However, numerical simulation gives opportunity to observe the phenomena of materials under different conditions without much cost. This paper investigated the behavior of square shaped specimens of AA7075 under varying impact velocities of impact velocities of $20 \mathrm{~m} / \mathrm{s}-50 \mathrm{~m} / \mathrm{s}$ of square striker bar of SHPB using Abaqus. To understand the importance of shape, striker bar and specimen shape are varying from square to circular under dynamic conditions. Results obtained under varying conditions indicated that the material behavior strongly dependent to the strain rates, striker shapes and specimen shapes.
\end{abstract}

Keywords: AA7075; numerical simulation; SHPB; square shape striker; square shape specimen

\section{INTRODUCTION}

To use the AA7075 under different dynamic conditions effectively, it is crucial to know the behavior under these conditions. Due to its high specific strength, AA7075 widely used in high strain rate range applications such as in automobiles, aerospace, and armors (Nishida et al., 2012; Liang et al. 2012). Hopkinson bar test, split Hopkinson bar test, Taylor impact test and optical techniques etc. are used to characterize the materials under high strain rates. These techniques are very costly and sometimes not easily available in many countries. 
To overcome this, many researchers use numerical methods to know the behavior of materials under different scenarios (Li \& Liu, 2018; Mi et al., 2018; Alaskari \& Oraby, 2018; Valdi et al. 2019; Sahnoune et al., 2020). In 1872, first time the dynamic tests were performed by using Hopkinson bar method (Hopkinson, 1872). After this, several methods such as more combinations of bars, different shapes of strikers, pulse shapers, lubrication techniques and finite element methods are implemented in split Hopkinson pressure bar (SHPB) to investigate the effect of these parameters under dynamic conditions (Hopkinson, 1914; Bancroft, 1941; Davies, 1948; Chen \& Luo, 2004; Lu \& Li, 2010; Clote et al., 2009; Song et al., 2009; Bekker et al., 2015; Baranowski et al., 2015; Chen et al., 2003; Kajberg \& Sundin, 2013; Fakimi et al., 2018; Afdhal et al., 2017). Dynamic behaviour of aluminium 6061 under high strain rates had been examined by using numerical simulation of SHPB under varying length (200 $\mathrm{mm}$ to 350 $\mathrm{mm}$ ) of striker bar (Shu et al., 2018). Bobbili et al. $(2015,2016)$ studied the characteristics of Al7017 under high strain rates and observed that the material strength was increased with increase in strain rates in dynamic conditions. Al 2024 and 7075 was analyzed at high impact velocities of impactor by Xing et al. (2013) and found that the 7075 was more crashworthiness efficient than 2024 for same speed of impactor. Pure copper under dynamic conditions are studied by means of SHPB methods and found that the yield strength (YS) and ultimate compressive strength (UCS) increased at high strain rates (Sulaiman et al., 2019). Scapin et al. (2014) studied the dynamic behavior of copper at high temperatures $\left(25-400^{\circ} \mathrm{C}\right)$ using $\mathrm{SHPB}$ and found that the copper was sensitive to both strain rate and temperature. It was observed that the ultimate strength of the material was highest for maximum length of striker bar. Experimental and numerical methods were applied by Xia et al. (2020) to see the influences of striker bar velocities $(4.590-8.791 \mathrm{~m} / \mathrm{s})$ under dynamic strain rate loadings. SHPB. To observe the specimen's shape under high strain rates, Zhang et al. (2019) numerically studied the hat shaped specimens of magnesium alloy using SHPB simulations. Baranowski et al. (2013) investigated the pulse shaper effect under dynamic loading using numerical simulation and concluded that the pulse shaper reduces the maximum strength of material. SHPB bar alignment and specimen's shape are investigated using finite element simulations (Chen, 2018). Based on literatures available, it can be understood that the dynamic behavior of any material depends on various components of split Hopkinson pressure bar such striker shapes, striker speed, striker length, bar geometry etc. It is also found that there is a large knowledge gap that exists in the literature in terms of determination of behavior of AA7075 under large strain rate especially 
with the square shape of strikers of SHPB with square shaped of specimens. To bridge the knowledge gap, the present work aims to understand the stress-strain response of AA7075 under large strain range through rigorous numerical studies on copper are performed under varying velocities of square striker bar and varying shapes of striker bar in SHPB simulation.

\section{METHODOLOGY}

The main parts of SHPB are striker bar, input bar, output bar and damper as shown in figure 1 . Strain gauges are attached at the middle section of the input and output bars which are used to measure the waves propagated through the bars. After getting the waves, we find the strain rate $\left(\dot{\varepsilon}_{s}\right)$, strain $\left(\varepsilon_{s}\right)$, and stress $\left(\sigma_{s}\right)$ of specimens using equations 1-3 (Kolsky, 1948):

$$
\begin{aligned}
& \dot{\varepsilon}_{s}(t)=-\frac{2 C_{0}}{L_{s}} \varepsilon_{r}(t) \\
& \varepsilon_{s}(t)=-\frac{2 C_{0}}{L_{s}} \int_{0}^{t} \varepsilon_{r}(t) d t \\
& \sigma_{s}(t)=E_{b} \frac{A_{b}}{A_{s}} \varepsilon_{t}(t)
\end{aligned}
$$

Where $C_{0}$ is wave velocity in the bar; $L_{s}$ is length of specimen; $E_{b}$ is the modulus of elasticity of bar; $A_{b}$ and $A_{s}$ are the cross-sectional area of bar and sample respectively; $\mathrm{t}$ is the time.

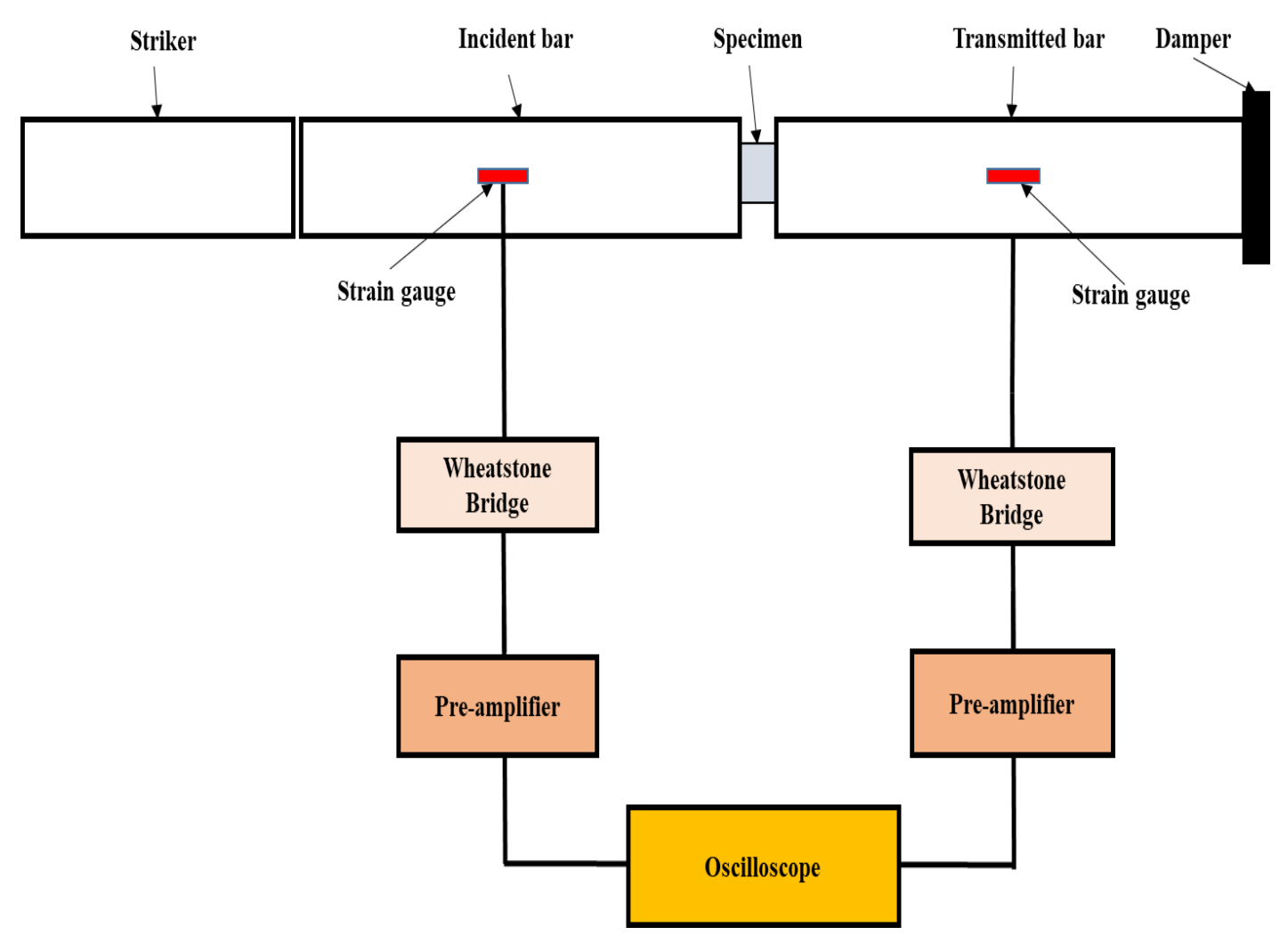

Figure 1 Schematic diagram of SHPB 


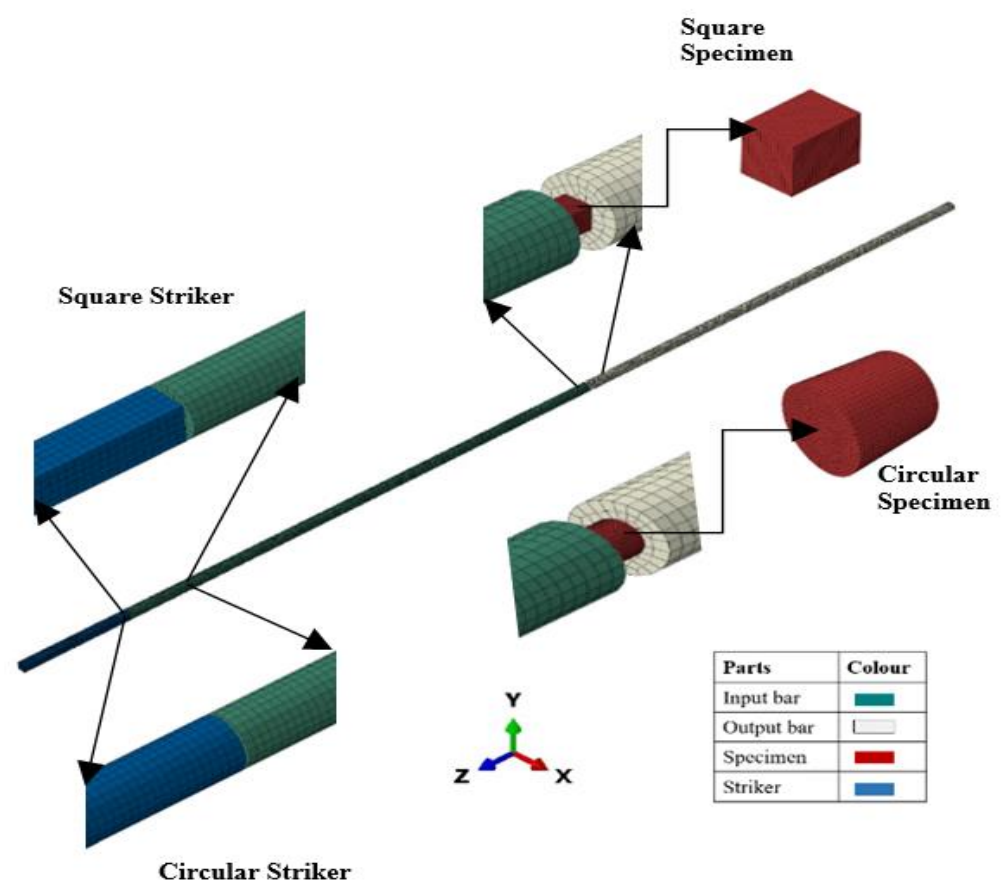

Figure 2 3D model of SHPB with shapes of strikers and specimens

Each part of SHPB model and specimens are modelled in ABAQUS/CAE (Abaqus, 2014) and as illustrated in figure 2. The zoomed section of striker-input bar and input bar-specimen-output bar interfaces of different SHPB assembly used for simulation in this paper have also been presented in figure 2. Two types of strikers (square and circular shaped) and two types of specimens (square and circular shaped) are used to comprehend the result of striker and sample geometry in high strain rate. The input and output bar of SHPB are having equal length and diameter, $1000 \mathrm{~mm}$ and $20 \mathrm{~mm}$, respectively. Striker bars having different cross-sectional dimensions with same length of $200 \mathrm{~mm}$. Detailed dimensions and geometries of different striker bars and specimens are presented in table 1. Mild steel [21] is considered as striker, input and output bar material, and AA7075 is taken for specimen materials. Density, elastic modulus and Poisson's ratio for materials are as: $7800 \mathrm{Kg} / \mathrm{m}^{3}, 200 \mathrm{GPa}$ and 0.3 for Mild steel; $2700 \mathrm{Kg} / \mathrm{m}^{3}$, $70 \mathrm{GPa}$ and 0.3, respectively for AA 7075. Plasticity part of AA 7075 is also given as JohnsonCook parameters available in literature (Børvik et al., 2010 \& Brar et al., 2009). Details of specimens and bar materials properties are discussed in author another paper (Gupta, 2021).

Table 1 Geometric dimensions of bars and specimens

\begin{tabular}{|l|c|l|}
\hline \multicolumn{2}{|c|}{ Parameter } & Dimensions (mm) \\
\hline \multirow{2}{*}{} & Square & $\mathrm{L}=200, \mathrm{~S}=14.14$ \\
\cline { 2 - 3 } & Circular & $\mathrm{L}=200, \mathrm{D}=20$ \\
\hline
\end{tabular}




\begin{tabular}{|c|c|c|}
\hline \multicolumn{2}{|l|}{ Input bar } & $L=1000, D=20$ \\
\hline \multicolumn{2}{|l|}{ Output bar } & $\mathrm{L}=1000, \mathrm{D}=20$ \\
\hline & Square & $\mathrm{L}=10, \mathrm{~S}=7.07$ \\
\hline & Circular & $\mathrm{L}=10, \mathrm{D}=10$ \\
\hline
\end{tabular}

Where $\mathrm{L}=$ length, $\mathrm{D}=$ diameter and $\mathrm{S}=$ side of the square

Each bar and specimens are meshed using C3D8R elements having mesh size of 0.5 and 0.28 $\mathrm{mm}$ respectively. Table 3 represents the number of elements and nodes for each condition of simulation. A general interaction algorithm is used between the boundaries of the bar and sample. For the proper boundary conditions, velocity is applied at the right end of the striker bar and the last end of the output bar is uncatered. To produce the high strain rate, the square striker bar is impacted at rate of $20,30,40$ and $50 \mathrm{~m} / \mathrm{s}$ by eeping the square specimen between the input and output bars.

Table 3 Total number of elements and nodes

\begin{tabular}{|l|c|c|c|}
\hline \multicolumn{2}{|c|}{ Factors } & Elements & Nodes \\
\hline & $20 \mathrm{~m} / \mathrm{s}$ & 42109 & 52425 \\
\cline { 2 - 4 } & $30 \mathrm{~m} / \mathrm{s}$ & 42109 & 52425 \\
\cline { 2 - 4 } & $40 \mathrm{~m} / \mathrm{s}$ & 42109 & 52425 \\
\cline { 2 - 4 } & $50 \mathrm{~m} / \mathrm{s}$ & 42109 & 52425 \\
\hline & Square & 42109 & 52425 \\
\cline { 2 - 4 } & Circular & 44239 & 54657 \\
\hline & Square & 42109 & 52425 \\
\cline { 2 - 4 } & Circular & 47769 & 58452 \\
\hline
\end{tabular}

For validation purpose of numerical approach applied here, the same methods have been used for results provided by Afdal et al. (2016) for Al6063 by keeping the same conditions as discussed in the paper. The details of the validation approach is discussed elsewhere (Gupta, 2021) and, for the reasons of brevity are not repeated here.

\section{RESULTS AND DISCUSSION}

Present study discussed the effect of strain rate, striker bar's shape and specimen's shape on the behavior of AA7075 using split Hopkinson pressure bar simulation in Abaqus 6.14.

To know the characteristics of alloy at high velocities, the square striker bar is impacted with 20$50 \mathrm{~m} / \mathrm{s}$ to the input bar for square shaped specimen. Effect of striker velocities to the waves propagated through bars and true stress strain curves are shown in Figure 3. It can be seen from figure 3a, the striker velocities change the peak values and durations of the propagated waves. Peak values and durations of each wave are highest and lowest for $50 \mathrm{~m} / \mathrm{s}$ and $20 \mathrm{~m} / \mathrm{s}$, respectively. Similarly, the striker velocities also influence the flow behavior of AA7075 as 
illustrated in figure $3 \mathrm{~b}$. It is found that the as the velocity of the square shaped striker increased from $20 \mathrm{~m} / \mathrm{s}$ to $50 \mathrm{~m} / \mathrm{s}$, true YS decreased whereas UCS increased. Thus, the nature of waves and flow curves both are affected under the change in speed of square striker.
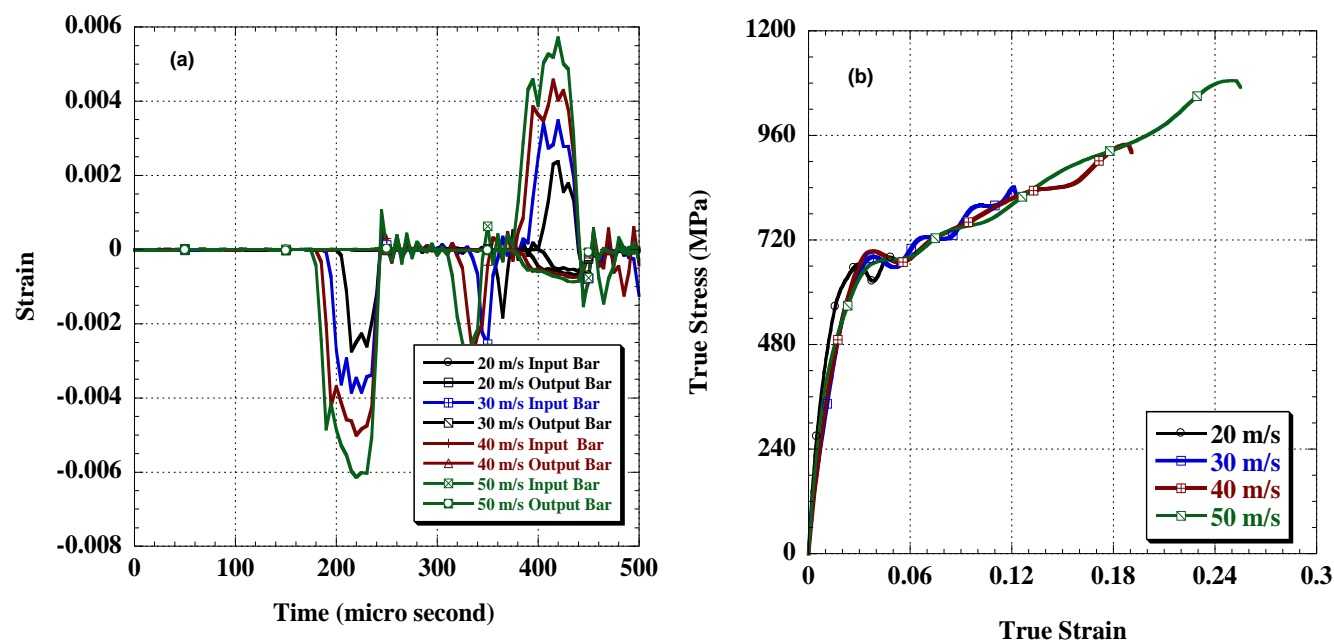

Figure 3 Striker velocities effects on (a) different waves of bars and (b) flow curves of alloy

To identify the influence of shape of striker bar, the square shaped striker is replaced by circular striker and the impact velocity is kept constant as $20 \mathrm{~m} / \mathrm{s}$. Here, diameter of the circular striker is taken as $20 \mathrm{~mm}$ and length kept same as for square one i.e. $200 \mathrm{~mm}$. Figure 4 illustrates the waves propagated through the bars and flow curves of material under variations of shapes in striker bar from square to circular by keeping the same square shaped specimens. From figure $4 \mathrm{a}$, it is observed that the wave propagated through input bar is affected while the wave propagates through output bar is unaffected. This is due to the only direct interaction of striker bar to the input bar. Flow curves of AA7075 under varying conditions of striker's shapes (Figure 4b) indicates that the behavior of the material is altered by the change in shapes of strikers for the same specimen. Both true YS and UCS are increased as the shape transformed from square to circular.

Shape of specimen is changed from square to circular to observe the influences of specimen's shape under dynamic condition. Here the diameter of circular specimen is taken as $10 \mathrm{~mm}$ and length is kept $10 \mathrm{~mm}$ as in case of square specimen. Both the specimens are impacted with the square shaped striker at the rate of $20 \mathrm{~m} / \mathrm{s}$. Figure 5 depicts the effect of specimen's shapes on the curve of alloy and wave propagated through bars for square striker. It is observed from figure $5 \mathrm{a}$, no change in shape and size of incident waves are found while the reflected and transmitted waves are affected by changing the shape of specimen. 

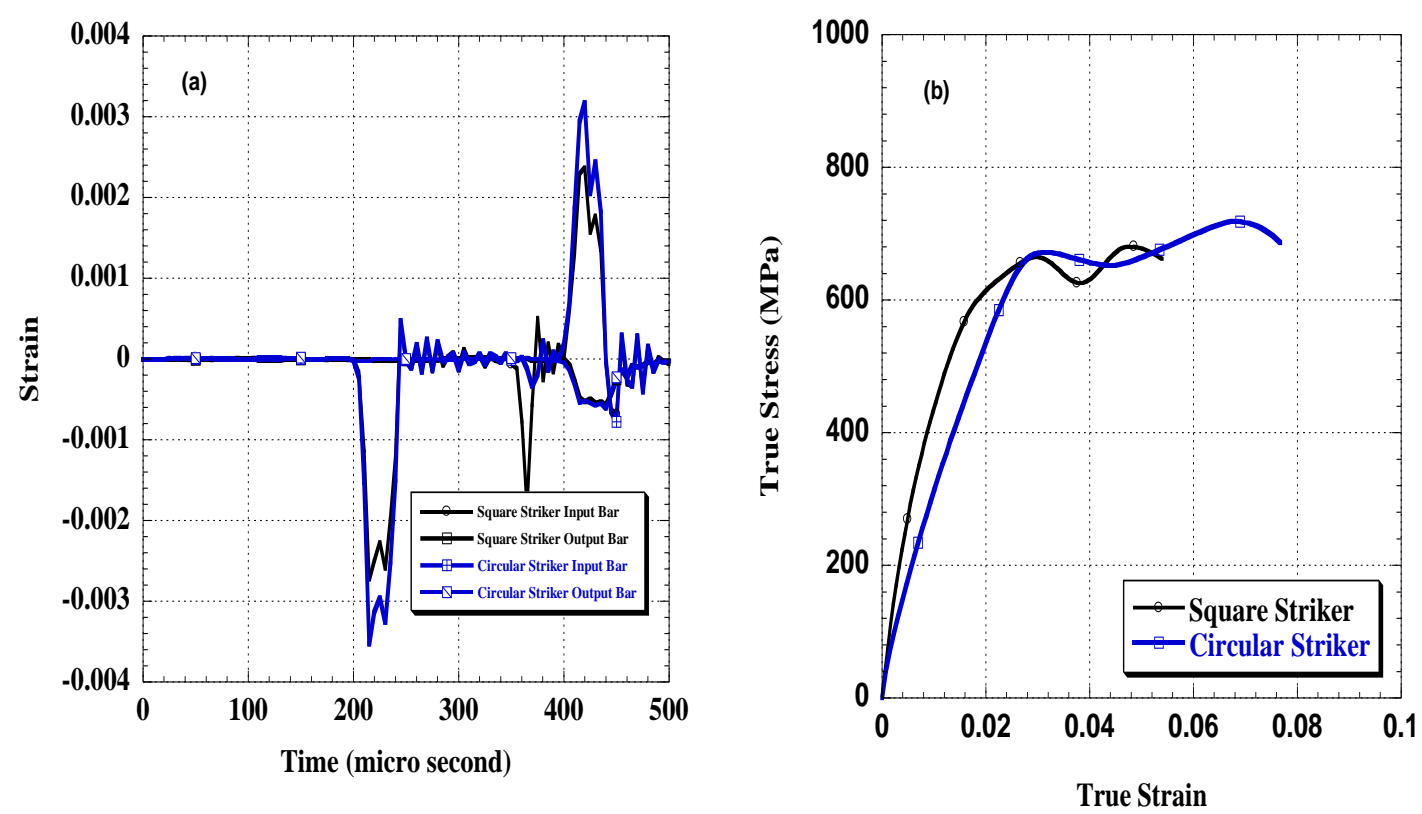

Figure 4 Striker's effects on (a) different waves of bars and (b) flow curves of alloy

True stress strain curve of AA7075 is also affected as change in shape of specimen from square to circular as shown in figure $5 \mathrm{~b}$. The true yield strength increased whereas the ultimate compressive strength are almost same as the specimen' shape changed from square to circular.

Results obtained under different conditions are summarized in table 4. It is found from table 4 that true YS decreased while true UCS and total compressive strength of AA7075 increased on increasing the velocity of square shaped striker. As the velocity of striker increases from 20$50 \mathrm{~m} / \mathrm{s}$, the ultimate compressive strength and total compression increased by $60 \%$ and $370 \%$ respectively whereas true yield strength decreased by $17 \%$. The true yield strength decreased by $4 \%$ while ultimate compressive strength increased by $5 \%$ on change in shape of striker bar from square to circular for square shaped specimen. Total compression is also increased by approximately $40 \%$ for circular shape of striker. When the shape of specimen changed from square to circular, the true yield strength increased by $29 \%$ while the ultimate compressive strength and total compression remains almost same. 

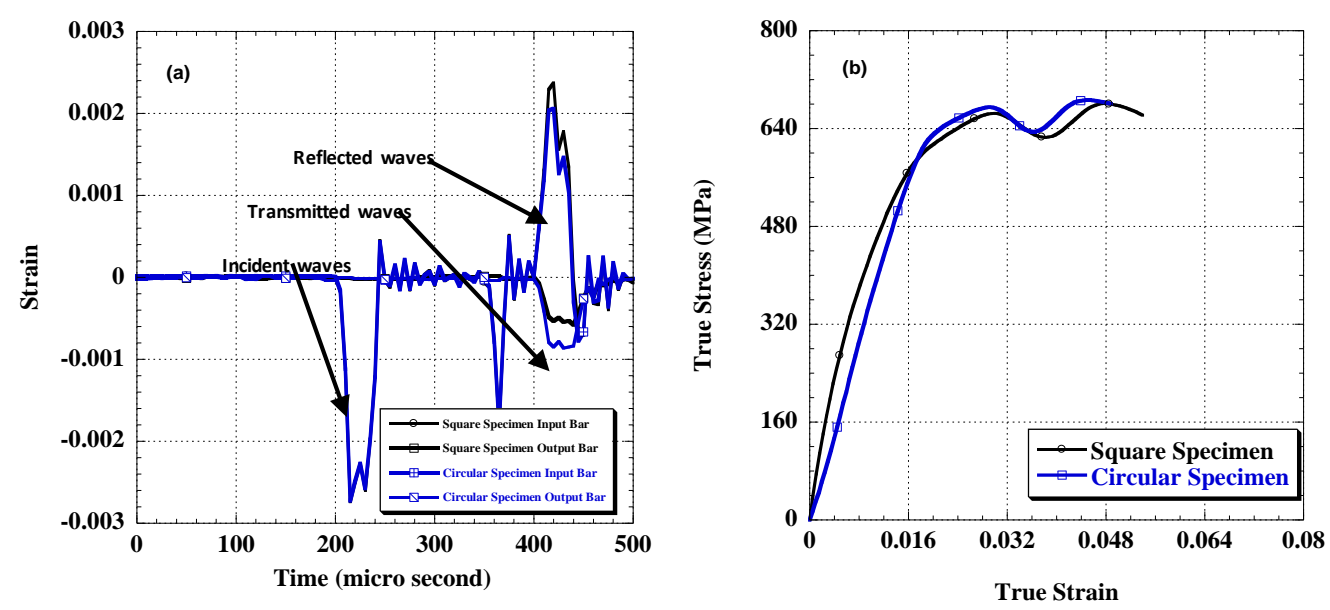

Figure 5 Specimen's effects on (a) different waves of bars and (b) flow curves of alloy

Table 4 Properties obtained for different factors

\begin{tabular}{|c|c|c|c|c|}
\hline \multicolumn{2}{|c|}{ Factors } & $\begin{array}{c}\text { True YS } \\
(\mathrm{MPa})\end{array}$ & $\begin{array}{c}\text { True UCS } \\
(\mathrm{MPa})\end{array}$ & $\begin{array}{c}\text { Total } \\
\text { Compression } \\
(\%)\end{array}$ \\
\hline \multirow{3}{*}{} & $20 \mathrm{~m} / \mathrm{s}$ & $474 \pm 1$ & $680 \pm 2$ & $5.39 \pm 0.1$ \\
\cline { 2 - 5 } & $30 \mathrm{~m} / \mathrm{s}$ & $434 \pm 2$ & $838 \pm 2$ & $12.22 \pm 0.1$ \\
\cline { 2 - 5 } & $40 \mathrm{~m} / \mathrm{s}$ & $417 \pm 3$ & $939 \pm 2$ & $19.01 \pm 0.2$ \\
\cline { 2 - 5 } & $50 \mathrm{~m} / \mathrm{s}$ & $392 \pm 1$ & $1086 \pm 1$ & $25.55 \pm 0.2$ \\
\hline & Square & $474 \pm 1$ & $680 \pm 2$ & $5.39 \pm 0.1$ \\
\cline { 2 - 5 } & Circular & $455 \pm 1$ & $718 \pm 2$ & $7.67 \pm 0.3$ \\
\hline & Square & $474 \pm 1$ & $680 \pm 2$ & $5.39 \pm 0.1$ \\
\cline { 2 - 5 } & Circular & $615 \pm 1$ & $684 \pm 2$ & $4.75 \pm 0.3$ \\
\hline
\end{tabular}

\section{CONCLUSION}

This paper numerically examined the characteristics of AA7075 under high strain rates by using Abaqus software. SHPB simulations were performed with change in shape and velocity striker bar and change in shape of specimen. Results indicated that the peak values of waves increased as the striker velocity increased. As the square striker velocity increased, the ultimate strength increased i.e. the materials shows positive strain rate sensitivity for UCS; whereas the YS shows negative strain rate sensitivity. Material behavior also changed under the influences of striker's bar shape. For circular striker with square shaped specimen at velocity $20 \mathrm{~m} / \mathrm{s}$, true YS decreased while UCS increased. Similarly for change in specimen i.e. for circular specimen with square shaped striker impacting at velocity $20 \mathrm{~m} / \mathrm{s}$ having greater true yield strength and almost same ultimate compressive strength. Total compression of the material is also affected under these conditions. 


\section{ACKNOWLEGMENT}

The author gratefully acknowledges National Institute of Technology Patna, India for Manish Kumar Gupta Ph.D. scholarships.

\section{REFERENCES}

Abaqus 2014. Abaqus user's Manual. Version 6.14. Dassault Systemes Simulia Corp. Providence, RI, USA.

Afdhal, Annisa, J., Muhammad, A.K. \& Leonardo, G. 2016. Development of a numerical model for simulations of split Hopkinson pressure bar. ARPN Journal of Engineering and Applied Sciences, VOL. 11, NO. 10.

Alaskari, A.M. \& Oraby, S.E. 2018. Adaptive control simulation to optimize metal removal for rough turning. Journal of Engineering Research Vol. 6 No. (2) pp. 209-231.

Bancroft, D. 1941. The velocity of longitudinal Waves in cylindrical Bars. Physical Review 59 pp 588-593.

Baranowski, P., Małachowski, J., Gieleta, R., Damaziak, K., Mazurkiewicz L. \& Kolodziejczyk, D. 2013. Numerical study for determination of pulse shaping design variables in SHPB apparatus. Bull. Pol. Acad. Sci. Tech. Sci. 61pp 459-466.

Bekker, A., Cloete, T., Chinsamy-Turan, A., Nurick, G. and Kok, S. 2015. Constant strain rate compression of bovine cortical bone on the Split-Hopkinson Pressure Bar. Mater. Sci. Eng. C 46 pp 443-449.

Bobbili. R., Madhu. V. \& Gogia, A.K. 2016. Tensile behaviour of aluminium 7017 alloy at various temperatures and strain rates. J Mater Res Technol. 5(2) pp 190-7.

Bobbili. R., Ramakrishna, B., Madhu. V. \& Gogia, A.K. 2015. Prediction of flow stress of 7017 aluminium alloy under high strain rate compression at elevated temperatures. Defence Technol. 11 Pp 93-8.

Børvik, T., Hopperstad, O.S. \& Pedersen, K.O. 2010. Quasi-brittle fracture during structural impact of AA7075-T651 aluminium plates. Int J Impact Eng., 37(5) pp 537-551.

Brar, N.S., Joshi, V.S. \& Harris, B.W. 2009. Constitutive model constants for A17075-T651 and Al7075-T6. AIP Conf Proc., 1195(1) pp 945-948.

Chen, S. 2018. Numerical Simulation of Split-Hopkinson Pressure Bar Test on High-Density Polyethylene. Chemical Engineering Transactions 66 pp 271-276. 
Chen, W. \& Luo, H. 2004. Dynamic compressive responses of intact and damaged ceramics from a single split Hopkinson pressure bar experiment. Exp. Mech. 44 pp 295-299.

Chen, W., Song, B., Frew, D. J. \& Forrestal, M. J. 2003. Dynamic small strain measurements of a metal specimen with a split Hopkinson pressure bar. Exp. Mech. 43 pp 20-23.

Cloete, T., Van Der Westhuizen, A., Kok, S. \& Nurick, G.N. 2009. A tapered striker pulse shaping technique for uniform strain rate dynamic compression of bovine bone. In DYMAT-International Conference on the Mechanical and Physical Behaviour of Materials under Dynamic Loading, Brussels, Belgium, pp 7-11 September 2009.

Davies, R.M. 1948. A critical study of the Hopkinson pressure bar. Phil. Trans. R. Soc. A240 pp 375-457.

Dorogoy, A., Karp, B. \& Rittel, D. 2011. A Shear Compression Disk Specimen with Controlled Stress Triaxiality under Quasi-Static Loading. Exp Mech., 51(9) pp1545-1557.

Fakimi, A., Azdhari, P. \& Kimberly, J. 2018. Physical and numerical evaluation of rock strength in Split Hopkinson Pressure Bar Testing. Computers and geotechnics 102 pp1-11.

Gupta, M.K. 2021. Numerical simulation of AA7075 under high strain rate with different shape of striker of split Hopkinson Pressure bar. Materials today communications 26 pp 102178.

Hall, I.W. \& Guden, M. 2003. Split Hopkinson pressure bar compression testing of an aluminum alloy: Effect of lubricant type. J. Mater. Sci. Lett. 22 pp 1533-1535.

Hopkinson, B. 1914. A method of measuring the pressure produced in the detonation of high explosives or by the impact of bullets. Philosophical Transactions of the Royal Society of London Series A: Mathematical, Physical and Engineering Sciences, 213 (497-508) pp 437-56.

Hopkinson, J. 1872. On the rupture of iron wire by a blow. Proc. Manchester Literary Philosophical Society, 11 pp 40-45.

Johnson, G.R. \& Cook, W.H. 1983. A constitutive model for metals subjected to large strains, high strain rates and high temperatures. Proceedings of the Seventh International Symposium on Ballistics, Hague, the Netherlands, 19-21 April; Volume 54 pp. 1-7.

Kajberg, J. \& Sundin, K.G. 2013. Material characterisation using high-temperature Split Hopkinson pressure bar. J. Mater. Process. Technol. 213 pp 522-531. 
Kolsky, H. 1948. An investigation of the mechanical properties of materials at very high rates of loading. Proceedings Physics Society. London: Institute of Physics (Journal) Ltd., pp 676-700.

Lee W. S. \& Lin, C. F. 2001. Impact properties and microstructure evolution of 304L stainless steel. Mater. Sci. Eng. A 308 pp 124-135.

Li, Q.M. \& Liu, E.L. 2018. Numerical analysis of wetting-induced deformation of rockfill dams. Journal of Engg. Research Vol. 5 No. (6) pp. 1-14.

Liang, X. P., Li, H. Z., Huang, L., Hong, T., Ma, B. \& Liu, Y. 2012. Microstructural evolution of 2519-T87 aluminum alloy obliquely impacted by projectile with velocity of $816 \mathrm{~m} / \mathrm{s}$. Transactions of Nonferrous Metals Society of China 22 pp1270-1279.

Lu, Y. \& Li, Q. 2010. Appraisal of Pulse-Shaping Technique in Split Hopkinson Pressure Bar Tests for Brittle Materials. Int. J. Prot. Struct. 1 pp 363-390.

Meng, H. \& Li, Q.M. 2003. Correlation between the accuracy of a SHPB test and the stress uniformity based on numerical experiments. Int. J. Impact Eng. 28 pp 537-555.

Mi, B., Zhan, H. \& Chen, B. 2020. Numerical simulation of static and dynamic aerodynamics for formation flight with UCAVs. Journal of Engg. Research Vol. 6 No. (3) pp. 203-224.

Nishida, M., Hayashi, K., Nakagawa, J. \& Ito, Y. 2012. Influence of temperature on crater and ejecta size following hypervelocity impact of aluminum alloy spheres on thick aluminum alloy targets. International Journal of Impact Engineering 42 pp 37-47.

Sahnoune, K., Benbrik, A., Mansour, A.S. \& Oussama, R. 2020. Flow simulation and performance analysis of a drilling turbine. Journal of Engg. Research Vol. 8 No. (3) pp. 203-224.

Scapin, M., Peroni, L. \& Fichera, C. 2014. Investigation of dynamic behaviour of copper at high temperature. Materials at High Temperatures Vol. 31 pp 131-140.

Shu, D.W., Luo, C.Q. \& Lu, G.X. 2018. Numerical simulations of the influence of striker bar length on SHPB measurements. International Journal of Modern Physics B Vol. 22, Nos. $31 \& 32$ pp 5813-5818.

Song, B., Casem, D. \& Kimberley, J. 2009. Springer Science Business Media: Heidelberg. Germany, 1 pp 901-907. 
Sulaiman, S., Nemati, J., Majzoobi G.H. \& AlJermi, M. 2019. Experimental and numerical study of high strain rate property of pure copper processed by ECAE method. Advances in Materials and Processing Technologies 5:3 pp 386-393.

Ta sdemirci, A., Ergönenç, C. \& Güden, M. 2010. Split Hopkinson pressure bar multiple reloading and modeling of a $316 \mathrm{~L}$ stainless steel metallic hollow sphere structure. Int. J. Impact Eng. 37 pp 250-259.

Valdi, M.H.T., Atrechian, M.R., Shalkoohy, A.J. \& Balasbaneh, A.T. 2019. Numerical study of seismic response of trapezoidal alluvial valleys against vertically propagating incident waves. Journal of Engg. Research Vol. 7 No. (4) pp. 37-57.

Xie, B., Chen, D., Ding, H., Wang, G. \& Yan, Z. 2020. Numerical Simulation of SplitHopkinson Pressure Bar Tests for the Combined Coal-Rock by Using the HolmquistJohnson-Cook Model and Case Analysis of Outburst. Advances in Civil Engineering, DOI https://doi.org/10.1155/2020/8833233.

Xing, M.Z., Wang, Y.G. \& Jiang, Z.X. 2013. Dynamic fracture behaviors of selected aluminium alloys under three-point bending. Defence Technol. 9. Pp 193-200.

Zencker, U. \& Clos, R. 1999. Limiting conditions for compression testing of flat specimens in the split Hopkinson pressure bar. Exp. Mech. 39 pp 343-348.

Zhang, F., Liu, Z., Mao, P., Wang, F. \& Liu, Y. 2019. Localized deform behavior of AZ31B magnesium alloy by numerical simulation. Materialwiss. Werkstofftech 50 pp 174-186. 